UDC: $821.134(7 / 8)^{\prime} 255.4$

DOI: https://doi.org/10.18485/beoiber.2021.5.1.5

\author{
Flavia Krauss ${ }^{1}$ \\ Universidade do Estado do Mato Grosso \\ Brasil
}

\title{
CONTRATRADUÇÕES LATINO-AMERICANAS E LEITURAS COLETIVAS NA ILHA-BRASIL
}

\begin{abstract}
Resumo
Este texto busca contribuir com uma possível inspiração para as didáticas dos estudos hispânicos no mundo. Para tanto, apresenta uma forma de trabalho que vem sendo desenvolvida no interior do Brasil, em Tangará da Serra, no Estado de Mato Grosso - região fronteiriça com a Bolívia. A partir de estudo anterior (Krauss 2016), dedicado a analisar o trabalho de editoras cartoneras, entendeu-se que seu catálogo é uma porta privilegiada para um trabalho linguístico e literário que se empenhe em ser contra-hegemônico (Palmeiro 2010, Navarro 2020). A experiência iniciou-se com o contato com uma editora boliviana cartonera e, posteriormente, formou-se um grupo de alunas dispostas a traduzir alguns de seus títulos para posterior publicação no Brasil. A esse trabalho, uma das autoras traduzidas, Virginia Ayllón, intitulou de contratradução, já que se coloca na contra-mão do que preponderantemente se traduz na América Latina. Ao longo do trabalho, percebeu-se um produtivo engajamento das alunas no processo de tradução, mas elas não se relacionavam muito entre si. Por essa razão, foi proposto um trabalho de leitura coletiva das obras que estavam sendo traduzidas. A metodologia adotada foram encontros semanais pela plataforma Google Meet para diálogo a respeito da obra que era lida. A partir de uma análise interpretativa das reuniões e de entrevistas individuais realizadas com todas as alunas-tradutoras, percebeu-se que essa é uma dinâmica que tem produzido efeitos positivos para a relação que as estudantes de língua espanhola estabelecem tanto com a língua quanto com sua literatura, mas, sobretudo, que esse é um circuito de trabalho que tem contribuído para a desconstrução de certo imaginário que ronda despectivamente nossos vizinhos bolivianos. Desse modo, a partir da transcrição das entrevistas e de trechos de nossos encontros, concluiu-se que essa seja uma prática que em muito tem colaborado para um aprimoramento da leitura da palavra que se oferece como suporte para uma melhoria da leitura de mundo das alunas.

Palavras-chave: literatura latino-americana, contratradução literária, tertúlias literárias dialógicas.
\end{abstract}

1 flaviakrauss@unemat.br 


\section{LATIN AMERICAN COUNTER-TRANSLATIONS AND COLLECTIVE READINGS IN ISLAND- BRAZIL}

\section{Summary}

In this text, contributing with a possible inspiration for the didactics of Hispanic studies in the world, I present a form of work that we are accomplishing in the countryside of Brazil, in a city called Tangará da Serra, located in the State of Mato Grosso - a border state with Bolivia. As we have previously studied (Krauss 2016) the literary-editorial work carried out by the Cartonera Publishers - collectives that manufacture books with cardboard covers and that have gained more and more literary expression in Latin America - we understand that their catalog is a privileged gateway for a linguistic and literary work that strives to be counter-hegemonic (Palmeiro 2010, Navarro 2020). For this reason, I contacted a Bolivian Cartonera Publisher and proposed to coordinate a group of students willing to translate some of their titles for later publication in Brazil. When I realized that the students were engaged in the translation process, but did not relate much to each other, I made a proposal of a work of collective reading of the works that are being translated. Therefore, we meet weekly on the Google Meet platform to talk about the work we are reading. From an interpretative analysis of the meetings themselves and also from individual interviews conducted with all student-translators, I notice that this is a sort of dynamic that has produced positive effects for the relationship that Spanish-speaking students establish so much with the Spanish language and its literature, but, above all, that this is a circuit of work that has contributed to the deconstruction of a certain imaginary that surrounds our Bolivian neighbors disparagingly. Thus, from this data, we concluded that this is a practice which has helped a lot for the improvement of the word reading that offers itself as a support to improve the reading of the world of the students.

Key words: Latin American literature, literary counter-translation, literary gathering.

\section{Introdução: os lugares que nos habitam}

Como forma de contribuir para este dossiê, tecemos esta reflexão, que se insere no campo das didáticas dos estudos hispânicos, mais especificamente, de uma didática possível em tempos de pandemia e distanciamento social, conforme a temos executado no interior do Estado do Mato Grosso, Brasil, pensando em um diálogo cultural com nossa vizinha Bolívia.

A experiência aqui descrita foi elaborada a partir de uma concepção de trabalho que preza mais pelo acontecimento (Pêcheux 1983) que pelo policiamento. Nesse âmbito, a proposta de ensino de língua e literaturas espanhola e hispano-americana aqui apresentada parte da noção de educação inspirada em Larrosa (2018: 36-37), por meio da qual o autor argumenta que:

a educação sempre tem a ver com uma vida que está mais além da nossa própria vida, com um tempo que está mais além de nosso próprio tempo, com um mundo que está mais além de nosso próprio mundo... e como não gostamos desta vida, nem deste tempo, nem deste 
mundo, queríamos que os novos [...] pudessem viver uma vida digna, um tempo digno, um mundo em que não dê vergonha viver.

Trata-se, portanto, de um trabalho que defende a educação como forma de construção de outro tempo, de renovação do mundo - como também propõe Arendt (2011) - porque pensa que seria uma vergonha deixar o mundo tal como se encontra para as gerações que nos seguem.

Tendo defendido o conceito de educação com o que trabalhamos, que em muitos sentidos se afasta do de doutrinação que vemos inundar as normativas educativas que nos chegam nessa parte do mundo, passamos agora a delimitar nosso problema: entendemos que em território latino-americano exista uma acentuada preponderância de uma epistemologia hegemônica eurocêntrica, envolvendo a imposição de certos expedientes que nos ditam o quê e o como devemos ensinar, também no que tange ao ensino de língua espanhola. No que tange ao quê, sabemos a partir de nossa vivência (e aqui privilegiamos um saber biográfico em detrimento do bibliográfico, porque há certos saberes sobre os quais simplesmente não se dizem ou se escrevem, ainda que atravessem nossas vidas e práticas) que as autoras bolivianas não fazem parte de um cânone latinoamericano. Nesse sentido, não figuram nas listas a serem ensinadas no Curso de Letras com Habilitação em Língua Espanhola. No que se relaciona ao como ensinar uma língua estrangeira, muitos são os autores que relatam que na atualidade o Método Gramática e Tradução recebe muitas críticas sobre sua eficácia no processo educativo (Lopes et al. 2017), de modo que, na história das metodologias de ensino de língua estrangeira, a tradução vem sendo ora evitada, ora totalmente ignorada (Tecchio y Bittencourt 2011), além de também notarmos que entre os professores existe uma notável rejeição a essa metodologia de ensino, como inclusive observa Schaeffer (s.d).

Ao termos delineado o conceito de educação com o qual trabalhamos e ao termos mapeado nosso problema, neste momento anunciamos desde que parte do mundo desenvolvemos nosso trabalho de professora de língua espanhola: do centro-oeste do Brasil, que, a partir de agora, trataremos de desenhar como uma Ilha-Brasil.

Rodrigues (2012) defende a hipótese de que o Brasil sempre foi percebido imaginariamente como uma ilha. A partir deste momento, refaremos o caminho discursivo percorrido pela autora: ao analisar o discurso jurídico-parlamentar que legisla ao redor da obrigatoriedade da oferta do ensino das línguas estrangeiras, com foco nas leis que versam sobre o ensino da língua espanhola, a autora percebeu que a metáfora de que o Brasil é uma «ilha de língua portuguesa no continente americano hispanofalante» se mostrou muito recorrente no interior do discurso que analisou e passou, assim, a interpretá-la como um pré-construído (Rodrigues 2012: 256).

Ao perseguir os sentidos aos quais essa metáfora poderia remeter, a autora mostranos que nos deparamos com o fato de que a denominação «Brasil» faz referência a uma 
ilha-fantasma localizada ao oeste da atual Irlanda e presente na cartografia medieval. No decorrer de seu trabalho, Rodrigues mostra que esse mito foi sofrendo deslocamentos e reformulações, mas que continua produzindo efeitos: durante toda a época de BrasilColônia, os portugueses exploraram a noção de que o Brasil era uma porção de terra insular, compreendida entre o delta amazônico e o estuário platino, para defender o fato de que o território Brasil era uma realidade anterior à colonização e justificar o renitente descumprimento do Tratado de Tordesilhas: «as representações se transformam, outros rios aparecem circundando o território da colônia portuguesa, mas, até meados do século XVIII, perdura a representação da Ilha-Brasil em mapas da América do Sul» (Rodrigues 2012: 258).

Por perceber os efeitos desse pré-construído nas relações cotidianas no estado do Mato Grosso, instiga-nos o lado de lá da fronteira e certa sensação de intransponibilidade que a permeia. Justamente por sabermos desse efeito, temos pensado, nos últimos anos, na capacidade presente na literatura, aqui entendida como um dom² (Lacan 1995: 156) de sensibilizar e, desse modo, tocar o corpo de quem a recebe, impulsionando assim a certo embrandecimento de algo da ordem do gozo fálico (Lacan 2008) que se expressa na ordem das leis, línguas e limites, tanto geográficos como subjetivos.

No que se refere ao âmbito legislativo, a lei brasileira (Brasil 11.161/2005), que instituía a obrigatoriedade da oferta de língua espanhola, em pouco alterou a relação estabelecida com os vizinhos bolivianos, como bem mostra o trabalho de conclusão de curso de Conceição (2019): a língua espanhola, ao estar vinculada aos imigrantes bolivianos, é colocada pelos alunos como objeto de rechaço e em pleno contexto escolar aparece por eles denominada como «língua de boliviano», em um sentido depreciativo que já antecipa o imaginário construído sobre o país vizinho.

Para ilustrar o que estamos dizendo, trazemos o depoimento de uma professora ao se referir ao preconceito existente com relação à língua espanhola - por ser colocada em estreita relação com a nacionalidade «boliviana» na cidade mato-grossense de Cáceres que faz fronteira seca com a Bolívia (Conceição 2019: 18):

As minhas aulas particularmente eu inicio sempre falando em espanhol, aí eles já começam a tirar sarro, a falar "você é boliviana, professora?", "a senhora sabe, eu não vou falar com boliviana, não vou ficar de entra e sai".

${ }^{2} \mathrm{O}$ dom é um conceito que o Lacan desenvolve dizendo que é a forma mais radical de valorização simbólica. Do ponto de vista antropológico - segundo Marcel Mauss (1974) o dom é uma das três regras sociais que organizam as sociedades arcaicas, tais regras são: dar, receber e retribuir. Do ponto de vista da constituição subjetiva, também há algo de muito arcaico na elaboração do dom, já que se refere ao momento em que a criança percebe que há algo que a ultrapassa naquilo que ela faz.

BEOIBERÍSTICA Vol. V / Número 1 (2021) | 73-89 
Nesse depoimento, uma recusa discursivamente assumida é construída, uma tomada de posição que se orgulha de ser feita, já que, em nossa leitura, a entendemos como um posicionamento em certa medida compartilhado pela comunidade, como se vislumbra na negociação com a interlocutora: «a senhora sabe, não vou ficar de entra e sai». Chamamos atenção à expressão «não vou ficar de entrar e sai» que, em nossa interpretação, guarda forte relação com as fronteiras, tanto geográficas quanto subjetivas, questão que aparece também na fala de outra professora (Conceição 2019: 21):

Olha tem um preconceito com a língua, nas escolas eles falam "ah eu não quero aprender boliviano". Isso em relação aos alunos, eles falam assim, então não sei... por conta da fronteira, por causa da questão negativa, dá a ideia do tráfico, que as pessoas associam, então eles têm uma ideia negativa sobre a língua.

A «fronteira» de saída já é tomada como um termo negativo, de modo que parece existir um pacto comunitário que diz que não se deve ficar de entra e sai por essa linha imaginária, sendo que o que é passado de um lado para o outro pode acabar sendo associado aos sentidos que orbitam ao redor do tráfico de drogas. Como estamos argumentando, existe um efeito de intransponibilidade que permeia a fronteira e que parece ser vigiado - para ser mais bem conservado - pelos habitantes da cidade de Cáceres, onde os dados foram colhidos. Cabe ressaltar que essa cidade tem fronteira seca com a Bolívia onde, antes da pandemia, existia um intenso fluxo mais de caráter econômico que social. Como estamos argumentando, não é suficiente a promulgação de uma lei de obrigatoriedade do ensino de determinada língua, se os corpos dos aprendizes não se apresentarem como terrenos férteis para seu trabalho.

\section{Brasil-Ilha: sobre habitâncias e possibilidades}

Ao pensar no efeito de intransponibilidade que ronda a linha imaginária que divide o Brasil da Bolívia (mas também une ambos os países), trazemos a voz de Roberto Oropeza, um dos editores atuais de Yerba Mala Cartonera, editora boliviana cartonera cujo catálogo está sendo traduzido por nós, que explicita sua versão sobre a desconexão Brasil-Bolívia, a partir da pergunta de uma aluna do curso de Letras de Tangará da Serra ${ }^{3}$ :

Alyne Gonçalves, a aluna-entrevistadora: Acá en Tangará da Serra estamos más cerca de Cochabamba que de São Paulo. Sin embargo, Cochabamba es una ciudad completamente

${ }^{3}$ Pergunta realizada no interior do «I Ciclo de Editores/Escritores Cartoneros» na Universidade do Estado do Mato Grosso e levado a cabo entre 17 de agosto e 9 de setembro de 2020. 
desconocida para nosotros. ¿A qué te parece que se deba este desconocimiento? En Cochabamba ¿saben ustedes alguna cosa sobre nosotros?

Roberto Oropeza, editor de Yerba Mala Cartonera: Ninguna. No, ninguna. Me estoy recién enterando de la existencia del nombre de la ciudad y de todo ¿no? Pienso que para nosotros Brasil es como un lugar lejano, ¿no? E inaccesible un poco. Y creo que tiene mucho que ver eso con el idioma, ahí está una barrera que nos separa y no podemos interactuar mucho, ¿no? Entonces las distancias pueden ser cortas, pequeñas, pero, no logramos conectarnos (...) Hay un muro invisible ahí que no nos permite imaginarnos que ustedes están tan cerca de nosotros. (grifos nossos)

Como lemos no depoimento de Oropeza, existe uma representação semelhante (ainda que simbolizada de modo distinto) à que habita o lado de cá dessa linha imaginária: «existe um muro invisível que não nos deixa imaginar que vocês estão tão perto da gente», traduzimos; «existe algo que não sabemos bem o que é porque não o enxergamos, mas que não nos deixar enxergar vocês», parafraseamos. Assim sendo, estamos muito próximos geograficamente, mas distantes simbolicamente, já que, ao que consta, «não conseguimos nos conectar».

Posicionando-nos para desenhar o lugar desde o qual escrevemos. Gostaríamos de dizer juntamente com Virginia Ayllón em um documentário que conta a história e os modos de ação de Yerba Mala Cartonera, bem como a relação contraditória que vivem os bolivianos com a palavra escrita": "yo no creo en las fronteras de los países para la literatura; no creo en ninguna frontera en la literatura». Acrescentamos: não só cremos que não existam fronteiras na literatura, como cremos que a literatura seja capaz de se infiltrar em todas as fronteiras.

Por essa razão, desde 2009, interessamo-nos pela potência que mobiliza os coletivos editoriais cartoneros. Esclarecemos que a palavra cartonero vem do significante espanhol cartón, papelão em português, sendo que cartonero corresponde ao catador de papelão, no Brasil. Os coletivos cartoneros publicam livros com capas de papelão. Esse modo de publicação e de confecção livresca teve sua ignição dada por Eloísa Cartonera, cujo projeto nasceu em 2003 e ainda funciona na cidade de Buenos Aires.

Em trabalho anterior (Krauss 2016) já havíamos argumentado que o fazer dos cartoneros se empenha em questionar, suspender a certeza de que existe uma contundente linha demarcatória entre o que serve e o que já não serve. Além disso, consideramos Eloísa Cartonera um acontecimento que rompe com um modo estabilizado historicamente na produção de livros na América Latina, abrindo um novo caminho para

${ }^{4}$ Esclarecemos ainda que esse documentário foi idealizado e concretizado pelo coletivo Yerba Mala conjuntamente com o Colectivo 7 e aparecerá em outras citações no decorrer deste artigo. Algumas de suas partes estão disponíveis no youtube, a citação em específico se encontra em:

https://www.youtube.com/watch?v=S_Kq19NVSlc\&t=472s. Acesso em: 28 de agosto de 2020.

BEOIBERÍSTICA Vol. V / Número 1 (2021) | 73-89 
uma rota de livros feitos com capa de papelão. Em termos metafóricos, entendemos, neste momento, que o trabalho do cartonero também esteja regido por um gozo suplementar que se sustenta na alegria do trabalho do entremeio (Celada 2010), na necessidade de conhecer e resgatar elementos que ficaram esquecidos do lado de lá da fronteira que insiste em estabelecer dicotomias a partir da qual um dos termos do par dicotômico necessariamente acaba sendo elevado à estatura do universal (Segato 2010).

Para além do interesse teórico, desde 2017 - sendo professora na Universidade do Estado do Mato Grosso - juntamente com algumas alunas do curso de Letras, trabalhamos com traduções de títulos cartoneros originalmente publicados em língua espanhola. Esse trabalho cooptou as alunas de tal modo que, ainda naquele ano, as discentes idealizaram e levaram a cabo a criação de uma editora cartonera na universidade. Trata-se da Curupira Cartonera, que em 2019 foi institucionalizada como um projeto de extensão. Nesse projeto, traduzimos alguns títulos de Eloísa Cartonera para o português, publicamos autores locais - na maioria das vezes os autores são os próprios alunos -, realizamos oficinas tanto de sensibilização literária e encadernação quanto de resgate de narrativas fundacionais indígenas.

Com a chegada da quarentena - devido à pandemia ocasionada pela COVID-19 demos um outro passo: no âmbito interno da universidade, aprovamos um projeto de extensão - ligado ao Programa Curupira Cartonera - intitulado «Leitura e Tradução Literária Cartonera». Esse projeto consistia em, a partir de um roteiro que incluía uma contextualização histórica e simbólica, conhecer um pouco da nossa contígua e ao mesmo tempo longínqua Bolívia, sua relação com a palavra escrita, bem como os modos de trabalho de uma editora cartonera localizada na cidade de Cochabamba - a Yerba Mala Cartonera. Em um acordo prévio feito com um de seus editores, as alunas escolheram os títulos que gostariam de traduzir ao português para posteriormente publicá-los em nossa cartonera. Cinco foram as alunas que se envolveram neste trabalho, sendo oito os títulos traduzidos.

Partindo da convicção de que não existem fronteiras para a literatura, pensamos que pudéssemos promover a aproximação entre algumas alunas - todas mulheres justamente via literatura: a literatura publicada por uma editora boliviana, que já havia se transformado em nossa parceira de trabalho. A partir de agora, descrevemos os modos de funcionamento de nossa parceira editorial boliviana: o local no qual miramos com vistas a transpor os efeitos resultantes da percepção do Brasil como uma ilha. 


\section{Os cartoneros do lado de lá da fronteira: Yerba Mala Cartonera}

Yerba Mala foi fundada em El Alto (Bolívia), por Crispín Portugal, Roberto Cáceres e Darío Manuel Luna, em 2006. No referido documentário sobre a cartonera, seus fundadores explicam o porquê do nome eleito. Conta Darío Manuel Luna ${ }^{5}$ " Como la yerba nunca muere y los libros conllevan en el fondo algo que jamás va a morir, son transcendentes. Por esa misma razón, nosotros nos hemos reunidos y hemos planteado si se podría llamar la editorial Yerba Mala Cartonera, Yerba Mala.»

Antes de ser uma cidade, El Alto era o bairro mais pobre de La Paz ${ }^{6}$. Yerba Mala Cartonera não só foi a primeira editora desta cidade, como surgiu com um ideal de democratização da leitura. Vejamos o que dizem seus fundadores na sequência do mesmo documentário, agora pela voz de Crispín Portugal: «Constituirnos también en un ente, digamos, de acceso fácil, ya que la yerba es una planta que crece en cualquier parte, en cualquier espacio». Segundo o depoimento, a cartonera não só tem como objetivo explícito a democratização da literatura, como também se propõe a ver o mundo de outra forma, como prossegue o próprio Cáceres: «En este sentido, de alguna manera estás llegando a gente que no accedía a esto y estás democratizando también ¿no? Estás pudiendo ser un poco más equitativo con la cultura y con la forma de mirar el mundo también ¿no?».

Fazemos notar que esse objetivo vai se radicalizar na fala de Crispín Portugal, quando defende que «outras formas de pensar podem ser e têm que ser respeitadas»:

El proyecto se ha prestado a contradecir muchas formas de concebir la literatura y esto ha generado más de una actitud o respuesta hostil hacia el proyecto y de alguna manera hacia la gente que forma parte de este proyecto. Pero creo que esto ha fortalecido nuestro compromiso, ha fortalecido nuestra convicción de entender y comprender que otro mundo es posible, que otras formas de pensar también pueden ser y tienen que ser respetadas. Tenemos muchísimo, muchísimo que recorrer. Yo creo que apenas hemos empezado, hemos iniciado un proceso que tiene que seguir adelante y que siento que, de alguna manera, si alguno de nosotros piensa, o está diezmado de las facultades para continuar este recorrido, creo que hay muchísima gente que viene detrás de nosotros y que esto no va a morir, no va a morir jamás.

Talvez o próprio Crispín se sentisse sem condições para tal empreitada quando fez esta declaração. Dia 18 de julho de 2007, ainda antes deste documentário estar finalizado,

${ }^{5}$ Disponível em: https://vimeo.com/12527550. Acesso em: 22 de novembro de 2015.

6 Segundo Virginia Ayllón, uma escritora publicada por Yerba Mala, em entrevista no documentário do coletivo: «No se olviden que El Alto es una ciudad muy joven, es la ciudad más joven del país, pero antes ¿qué era El Alto? Era el barrio más pobre de la ciudad de La Paz. Y ustedes saben que quienes han empezado a reciclar las cosas en nuestras ciudades antes del discurso medioambientalista han sido los pobres». Disponível em: http://vimeo.com/12417522. Acesso em: 11 de janeiro de 2016.

BEOIBERÍSTICA Vol. V / Número 1 (2021) | 73-89 
o autor se suicida tomando veneno para ratos. Ele deixa uma nota dizendo «siempre he pensado en morirme, menos un día como hoy» (Yerba Mala Cartonera 2007). Entretanto, outras pessoas disponibilizaram seus corpos e trabalho para que o coletivo não morresse e seguisse em funcionamento até hoje. Claudia Michel já se havia integrado ao grupo. Passado um tempo, ela mudou de cidade ao resolver viver em Cochabamba e trabalhar em um centro cultural: começa então a recrutar pessoas e a convocar atividades relacionadas à cartonera. Como os componentes que ficaram no El Alto se envolveram em projetos pessoais, Yerba Mala começou a se organizar e a se fixar em Cochabamba. $\mathrm{O}$ coletivo, atualmente, é constituído por Roberto Oropeza e Jazmine Ortiz.

Adentrando-nos um pouco sobre suas linhas de ação na contemporaneidade7, Roberto Oropeza conta-nos que suas propostas de ação nesse contexto pandêmico também se viram muito limitadas:

Alyne, a aluna-entrevistadora: Actualmente, ¿cuáles son las propuestas de trabajo de Yerba Mala?

Roberto Oropeza, o editor de Yerba Mala: Actualmente, en este año, yo creo que sobrevivir ¿no? Es un año de crisis para todas editoriales y estamos ahí conflictuados. Veo muchas presentaciones de libros online, la virtualidad... Y, hablando con los miembros de la editorial no nos sentimos muy a gusto con lo virtual para hacer actividades ¿no? Es algo que estamos intentando procesar. Nos gustaría volver a lo físico, a lo cara a cara, que era lo nuestro, participar en ferias, hacer lecturas, organizar festivales, que era a lo que estábamos dedicándonos. Justo este año nos tocaba organizar la III Feria del Libro Independiente acá en Cochabamba que se ha cancelado. En octubre organizábamos el Encuentro de Poesía Sudamericana, que también se ha cancelado...

Foi partindo da dificuldade relatada pelo editor de Yerba Mala, que em certa medida também era a dificuldade de Curupira Cartonera - tão afeiçoada ao trabalho presencial, tão feliz com os contatos interpessoais - que também começamos a mobilizar possibilidades para que pudéssemos colocar algo de nosso corpo em uma dinâmica simbólico-cultural que criasse um circuito de tradução e relação com a literatura colocada em circulação em um país vizinho ao nosso, mas invisibilizado pelo nosso. Foi quando surgiu o intuito de nos encontrarmos através do exercício de nos conectarmos à literatura produzida na América Latina: nos conectarmos via literatura.

Esse movimento começou em abril de 2020. A ação foi conversar com Roberto Oropeza, o atual editor do Yerba Mala, sobre a possibilidade de que traduzíssemos alguns títulos do seu catálogo. Era um desejo guardado há muito tempo fazer com que outras pessoas conhecessem o trabalho e o catálogo dessa editora que faz livros com capas de

${ }^{7}$ Em uma entrevista realizada no interior do «I Ciclo de Editores/Escritores Cartoneros», arquivo pessoal. 
papelão sem fins lucrativos. Algumas alunas também se empolgaram com a ideia. Conexão. Oito são os livros que começaram a ser traduzidos em 2020.

Em setembro daquele ano, percebemos que as alunas se conectavam às obras com as quais trabalhavam, mas pensamos que também poderia ser produtivo se elas se conectassem umas às outras. Por isso, propusemos um encontro virtual semanal com as alunas-tradutoras para que pudéssemos ler coletivamente as traduções já feitas por cada uma delas. Nosso primeiro encontro ocorreu dia $1^{\circ}$ de outubro. De lá para cá nos reunimos toda semana. Intitulamos nossos encontros de Ayni Literário, porque gostaríamos de fazer ressoar este significante aymara. «Ayni» seria a coluna vertebral do pensamento andino: significa partilha, com-partilha; é um princípio que entende que o universo se organiza em uma relação de complementariedade. Segundo González (2013: 03), «Ayni es una palabra aymara que es todo un concepto en sí mismo. Implica la contribución solidaria entre miembros de una misma comunidad».

Para dar um pouco mais de corpo à complementariedade presente no (e proposta pelo) ayni de Tangará da Serra, vale ressoar as palavras de Segato (2010), quem nos chama a atenção para o fato de que o mundo pré-intrusão não tratava a diferença de gênero como um binarismo, mas como uma complementariedade. Essa diferença de perspectiva, na verdade, é a matriz de toda a diferença entre o mundo pré-intrusão e o mundo moderno. Ao estabelecer uma relação binária entre todos os elementos do mundo moderno, consequentemente um dos elementos binários acaba sendo escolhido como o universal, de modo que o outro acaba sendo tomado como resto.

En el mundo de la modernidad no hay dualidad, hay binarismo. Mientras en la dualidad la relación es de complementariedad, la relación binaria es suplementar, un término suplementa -y no complementa- el otro. Cuando uno de esos términos se torna universal, es decir, de representatividad general, lo que era jerarquía se transforma en abismo, y el segundo término se vuelve resto: ésta es la estructura binaria, diferente de la dual. (Segato 2010: n.p.)

A partir da leitura de Segato (2010) e González (2013), interpretamos que no mundo andino a palavra ayni faz referência a esta outra matriz fundacional que estabelece que as diferenças entram em relação de complementariedade: se os encontros assim foram nomeados, foi porque gostaríamos que neles ressoasse essa outra matriz de sentidos.

Os moldes dos encontros foram inspirados nas tertúlias literárias dialógicas desenvolvidas na Comunidade de Aprendizagem La Verneda de San Martí, em Barcelona, na Espanha. Surgida em 1980, em um período de transição democrática após o fim da ditadura de Franco em 1975, seus idealizadores e realizadores muito se nutriram do pensamento do brasileiro Paulo Freire. Inclusive Lleras y Soler (2003: 26) citam o famoso educador para dizer onde está o núcleo principal da ação realizada com a Tertúlia Literária Dialógica: «la clave está en promover una comunicación cultural entre 
conocimiento popular y académico». Essa ideia apareceu, porque entre 2008 e 2009 participamos de uma tertúlia literária em um bairro cigano de uma cidade chamada Castelló de la Plana, na Espanha. Os encontros aconteciam em uma língua que até então desconhecíamos, o valenciano, mas algo se moveu em nós, mesmo a partir de tanto desconhecimento. Algo também permaneceu: até hoje nos sentimos conectados às pessoas que também participavam dessa tertúlia toda tarde de sexta-feira.

Tendo esclarecido de onde veio a ideia de um ayni, cumpre explicar seu modo de funcionamento: nosso ayni consiste em um encontro semanal pela plataforma Google Meet de duas horas no qual conversamos - entre o grupo de mulheres tradutoras que estão traduzindo cada qual uma obra do catálogo de Yerba Mala Cartonera - sobre algum livro escrito por uma escritora boliviana. Desse modo, então, já subvertemos um dos princípios das Tertúlias Literárias Dialógicas, justamente o que diz que o objetivo de tais encontros é democratizar o acesso aos clássicos da literatura.

Nas palavras de Lleras y Gallart (2003: 24): «Las obras seleccionadas son “clásicas" en el sentido que les son atribuidas ciertas características que las constituyen en importantes referentes de la cultura». Entretanto, em nosso ayni, não lemos os clássicos ${ }^{8}$. Lemos justamente latino-americanas que não entraram no cânone: as bolivianas. Começamos por Virginia Ayllón9: quão à frente de seu tempo é seu pensamento, quão lúcido é seu modo de compreensão do mundo. Na sequência começamos a ler Giovanna Rivero10: a escritora boliviana mais conhecida fora da Bolívia.

\section{Habitar o contra-hegemônico: nossas contratraduções}

Lemos as bolivianas, porque geograficamente estamos muito perto delas. Entretanto, elas sistematicamente não cabem no cânone da literatura latino-americana, não sendo levadas em consideração pelas instituições que trabalham com formação de professores de língua espanhola no Brasil. Assim, gostaríamos de fazer notar que interpretamos este gesto de leitura como uma tomada de posição, já que, nesse momento, reafirmamos nosso compromisso com o que Segato (2010) afirma ter sido transformado

8 Entendo que os clássicos estão justamente do lado do binarismo que se transformou em universal, conforme vamos alinhavando no decorrer deste texto, interessa-nos o resto, aquilo que foi apagado, rebaixado ao estatuto de invisível.

${ }^{9}$ Nasceu em La Paz, Bolívia, em 1958. É, atualmente, uma das vozes mais respeitadas e combativas da literatura, da academia e do feminismo boliviano. É escritora, editora, bibliotecária e crítica literária.

10 Nasceu em Santa Cruz de la Sierra, na Bolívia, em 1972. É um dos grandes destaques da literatura de seu país. Em 2011 foi eleita como um dos 25 segredos literários mais bem guardados da América Latina pela revista FIL Guadalajara. Foi professora de Semiótica e Jornalismo por anos em Santa Cruz, mas hoje vive nos Estados Unidos e trabalha com o ensino da escrita. 
em lixo, em refugo, pela lógica binária de funcionamento do mundo moderno. Há alguns anos entendemos (Krauss 2016) que a proposta cartonera, ao afastar o objeto livro de uma categoria meramente mercadológica ${ }^{11}$, seja uma porta de entrada privilegiada a um recorte da literatura latino-americana capaz de produzir certos deslocamentos em nossos modos de subjetivação hegemônicos, como colocado tanto por Palmeiro (2010) quanto por Navarro (2020).

A partir dessa visada, entendemos que, ao propormos uma discussão acerca da preponderância de uma epistemologia hegemônica eurocêntrica no território latinoamericano, envolvendo a imposição de certos expedientes que tendem a excluir determinadas manifestações culturais, apostamos na hipótese de que a literatura também seja capaz de produzir desvios de rota no processo de regulação de nossa sociedade.

Tratando de começar a tecer interpretações sobre o fato de traduzirmos a partir de um catálogo editorial boliviano e lermos escritoras bolivianas, trazemos as palavras da própria Virginia Ayllón - uma das autoras traduzidas e lidas em nosso Ayni Literário, no $8^{\circ}$ Encuentro Internacional de Editoriales Cartoneras ${ }^{12}$, realizado em Santiago no Chile, entre os dias 27 e 28 de novembro de 2020, ao se referir a nossa prática levada a cabo em Tangará da Serra:

Y me parece a mí que el discurso de traducción de las cartoneras es otra vez un contradiscurso (...) Entonces, tengo la impresión - es una hipótesis, es también un deseo, digamos - que la traducción cartonera, en realidad es otra forma de contracultura, es una contratraducción. Y yo celebro mucho esto.

A autora explica que na Bolívia se conhecem muitos referentes da literatura brasileira, mas nós (os brasileiros) não conhecemos quase nada da literatura boliviana não porque não tenhamos interesse, mas porque existe uma tendência hegemônica que os leva a conhecer o que produzimos aqui, mas não nos leva a conhecer o que produzem lá. Virginia Ayllón justifica sua interpretação que diz que ler e traduzir as bolivianas pode ser interpretado como um ato de contratradução, já que questiona o movimento tradutório majoritariamente realizado no interior da América Latina.

A fim de dar concretude ao que estamos executando, no fevereiro de 2021, apresentamos a primeira tradução feita por uma das alunas do projeto, como anuncia $o$ cartaz colocado na sequência. A apresentação foi feita nos moldes de uma live, transmitida

\footnotetext{
${ }^{11}$ Nas fichas catalográficas de seus livros, o Yerba Mala apresenta-se como um «proyecto social, cultural y comunitario sin fines de lucro».

${ }^{12}$ Neste link que dá acesso ao encontro, é possível retomar as discussões feitas nestes dois dias de encontro: https://www.youtube.com/watch?v=pjNkvWnRR30. Acesso em: 7 de fevereiro de 2021.
} 
pelo facebook ${ }^{13}$, dada a impossibilidade de nos encontrarmos presencialmente durante a pandemia.

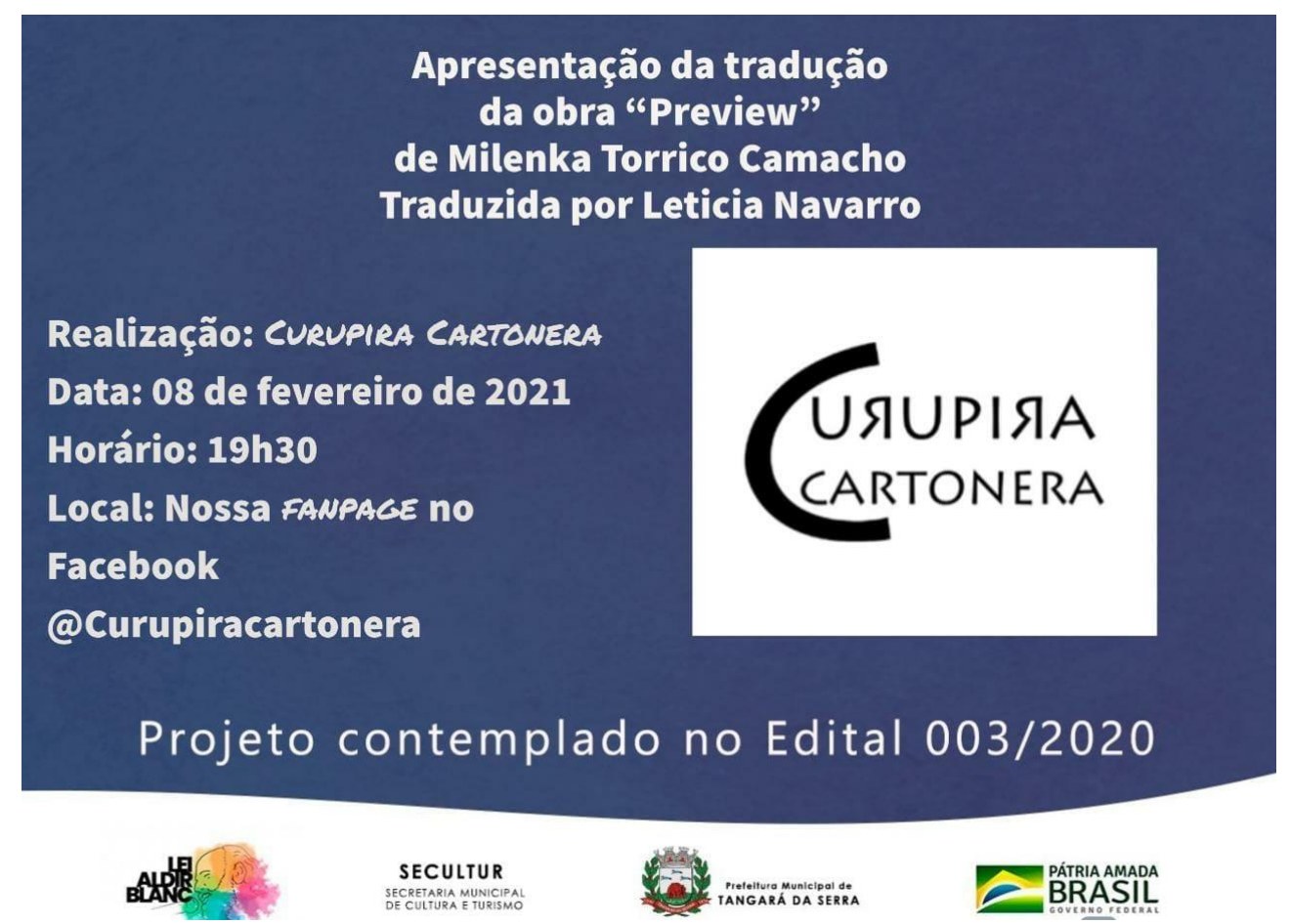

Fonte: Material de divulgação do evento

As outras apresentações já têm data prevista para acontecerem e ocorrerão ainda no primeiro semestre de 2021. Das ações apresentadas neste texto, resultou um projeto de pesquisa no qual mapeamos os deslocamentos subjetivos vivenciados pelas alunas que traduzem e/ou participam da leitura coletiva das obras - nosso Ayni Literário. O mais gratificante é nos depararmos com achados da pesquisa, como o que se segue, em conversa com Letícia Navarro, uma das alunas-tradutoras:

Eu: Letícia, no decorrer dessa conversa você foi me mostrando que o que ficou mais forte para você no processo de tradução é isso de mergulhar mais profundamente no texto e ter que voltar com ele, construindo sentidos na língua materna a partir do que você viu em língua estrangeira e foi essa atitude o que mais mudou em você, esse fôlego maior de ficar mais tempo mergulhada no texto. Como você ficava no rasinho, parece que você não conseguia muito respirar embaixo do texto, né? Então parece que você foi desenvolvendo

${ }^{13}$ A apresentação pode ser assistida por este link: https://fb.watch/3xEazaCQDk/. Acesso em: 7 de fevereiro de 2021. 
uma tecnologia para respirar mais dentro do texto. Com o desenvolvimento dessa tecnologia, você acha que alguma coisa mudou em você, Letícia?

Letícia: Mudou! A minha paciência para a leitura, porque eu lia sempre muito rápido qualquer texto eu lia sempre muito rápido, muitas vezes eu atropelava as palavras já para dar a minha interpretação. Eu lia papapapapapapapa, pronto, já isso. Agora não, na tradução eu tive que ter paciência porque eu lia, aí muitas vezes eu não compreendia, eu tinha que voltar lá do início, aí eu ia relendo tudo de novo, para quando chegasse lá naquela parte que eu tinha que traduzir, para eu poder entender. O que tava lá será que realmente era o que o texto anteriormente tava dizendo? Então o que mudou muito em mim foi a minha paciência para a leitura, que eu não tinha, não tinha nada, zero. Eu lia rápido, rápido ali e já ficava. Agora não, agora eu leio mais devagar. Eu leio com mais paciência: quando eu não entendo eu volto duas, três, quatro vezes e leio de novo, para minha interpretação melhorar. E isso ficou nítido assim nas traduções: paciência.

A partir da fala da aluna, vamos tecendo a interpretação de que a tradução também seria a tecitura de um dom, sendo um trabalho que leva a aluna para o lado de lá da fronteira da alteridade, já ciente da tarefa de ter de voltar com aqueles sentidos formulados em sua língua materna. Nesse cruzar de fronteiras, algo se perde, mas algo se ganha. Acreditamos que o que se perda seja ilusão de acreditar na relação biunívoca entre palavra e coisa, já que do lado de lá da fronteira os sentidos são construídos a partir do emprego de outras palavras, o que necessariamente nos leva à construção de outros sentidos, não totalmente traduzíveis. Ao se perder a ilusão na relação biunívoca entre palavra e coisa também se perde a ilusão de que existiriam traduções perfeitas entre as diferentes línguas, o que colocaria a tradução tecnicamente como no campo do impossível. Mas, justamente por tais sentidos não serem totalmente traduzíveis é que a tradutora se obriga a criar sentidos - e é justamente aí que se encontraria a dimensão artística da tradução.

Nessa dimensão artística, identificamos que exista algo da gestação de um dom: para trazer o texto da língua estrangeira para minha cultura, coloco algo de minha experiência, das palavras que me constituem, de meu corpo que experiencia o gosto dessas palavras que tanto prazer tenho em chamar de minhas, enchendo a boca para dizer "minha língua materna". Assim, a tradução é um processo criativo que abre a aluna para a experiência de que o texto e o mundo exigem uma leitura que não pare em "minha interpretação", pois, muitas vezes, não compreenderemos nem o texto, nem o mundo a partir de "nossa interpretação", nossa visão de mundo, quando essa interpretação se relaciona mais com expectativas e pré-construídos, do que com uma leitura propriamente dita. Em nosso entendimento, a alteridade exige uma interpretação que leve em conta sua materialidade em detrimento de meus pressupostos. Nesses termos, a experiência e o escrito do outro, ao serem traduzidos, também me obrigam a sair da ilha na qual eu também me constituo. 
Letícia, em sua entrevista, testemunha que antes de haver passado pelo processo de tradução lia muito rápido, "papapapapapapapa, pronto", o que não a permitia sair de si para ir até o outro e voltar a si construindo sentidos com sua própria língua. Havia algo em si que antecipava por conta própria os sentidos do lido. Havia algo em seu corpo que temia o texto, evitando-o e colocando sentidos imaginados por ela. Conforme indicia-nos seu depoimento, parece que após o processo de tradução de dois livros, algo de seu corpo deixou de temer o texto e a ele pode se entregar, por saber que sairia dessa experiência somada, acrescida de si e não subtraída. Ao entregar à comunidade uma tradução que leva algo de si, Letícia vivencia o dom, se abre à experiência de tradução, à cultura do outro, ao que existe do lado de lá da fronteira geográfica e subjetiva e sai desse processo enriquecida, sabendo que o processo pode ser demorado e dolorido, mas que vale a pena, já que é um processo que ela se propõe a fazer voluntariamente, para que sua interpretação melhore, como argumenta.

Ao dizer que o que ficou mais nítido em suas traduções tenha sido a elaboração de uma paciência para a leitura, a aluna oferece-nos indícios de que, talvez, também esteja se forjando uma paciência que dê conta de ler o outro em sua materialidade para além dos sentidos que constrói antecipadamente, seja a partir do que se veicula na mídia, seja a partir do que se formula como expectativas e referencial de valores.

Em nossas entrevistas e reuniões também temos tomado essa postura como um posicionamento a ser aprendido: existem forças e imaginários preponderantes, caso não prestemos muita atenção no lugar que ocupamos no mundo e nos esforcemos para pensar a partir do lugar que ocupamos, invariavelmente estaremos a serviço de certa hegemonia ideológica. Nessa reflexão, a partir de nossas contratraduções, reafirmamos nosso compromisso com o que ainda não havia sido visibilizado no interior da universidade, por entendermos que pode ser uma porta de acesso significativa à alteridade, já que se importa com quesitos de ordem mais técnica mas também com elementos que levem em consideração tanto aspectos mais relacionados a um imaginário de relação com o outro, quanto relacionados à subjetividade das tradutoras envolvidas.

Acreditamos que estarmos possibilitando a nossas alunas essa vivência tradutória entre duas culturas ao mesmo tempo próxima e distantes é uma oportunidade de ajudálas a ler o mundo em que vivem. Ainda que tenhamos certa vergonha de viver neste mundo, como trazido pela voz de Larrosa no começo desta reflexão, nos somamos a Melman (1992: 37) quando diz que a psicanálise - e aqui acrescentamos, o processo educativo - poderia permitir ao sujeito que participasse plenamente deste mundo, mesmo que seja doloroso, pois não há nenhum outro.

Oferecer oportunidades para que as alunas leiam, conheçam e participem de outros mundos dentro desse nosso mundo a partir de um processo de tradução é a aposta do nosso trabalho. 


\section{BIBLIOGRAFIA}

Arendt, Hannah. «A Crise na Educação.» Entre o Passado e o Futuro. 7.ed. São Paulo: Perspectiva, 2011. Impresso.

BRASIL. Lei $N^{\circ}$. 11.161, de 05 de agosto de 2005. Dispõe sobre o ensino da língua espanhola. Diário Oficial da União, Brasília, DF. Impresso.

Celada, María Teresa. «Entremeio español / portugués - errar, deseo, devenir.» Caracol 1 (2010): 110-150. Impresso.

Conceição, Mariele. Representações sobre o processo de ensino/aprendizagem da língua espanhola em contexto de fronteira - Cáceres/MT. Trabalho de Conclusão de Curso. Mato Grosso: Universidade do Estado do Mato Grosso, Campus Tangará de Serra, 2019. Web. 26 abr. 2021.

González, Magdalena. Ayni. Antología del cuento boliviano contemporáneo. Córdoba: La Sofía Cartonera, 2013. Impreso.

Krauss, Flavia. «O Acontecimento Eloísa Cartonera: memória e identificações.»Tese de doutorado. São Paulo: Faculdade de Filosofia, Letras e Ciências Humanas/Universidade de São Paulo, 2016. Impresso.

Lacan, Jacques. O seminário. Livro 4: a relação de objeto (1956-1957). Texto estabelecido por Jacques Alain Miller. Rio de Janeiro: Jorge Zahar, 1995. Impresso.

-. O Seminário. Livro 20: mais ainda (1972-1973). Texto estabelecido por Jacques Alain Miller. 3. ed. Rio de Janeiro: Jorge Zahar, 2008. Impresso.

Larrosa, Jorge. Tremores: escritos sobre experiência. Belo Horizonte: Autêntica Editora, 2018. Impresso.

Lopes, Rodrigo Smaha, et al. «Métodos/abordagens no ensino de línguas em uma sociedade multiletrada.» Tabuleiro de Letras 11.2 (2017): 196-208. Web. 26 abr. 2021.

Lleras, Jordi, y Marta Soler Gallart. «Las tertúlias literárias dialógicas: compartiendo lectura y cultura.» Saberes (Inverno 2003): 24-28. Web. 15 fev. 2021.

Mauss, Marcel. «Ensaio sobre a dádiva. Forma e razão da troca nas sociedades arcaicas.» Sociologia e Antropologia. v. II. São Paulo: Edusp, 1974. Impresso.

Melman, Charles. Imigrantes: incidências subjetivas das mudanças de língua e país. São Paulo: Escuta, 1992. Impresso.

Navarro, Letícia. «La lengua de las locas: um pequeno recorte sobre o catálogo de Eloísa Cartonera.» Trabalho de Conclusão de Curso. Mato Grosso: Universidade do Estado do Mato Grosso, Campus Tangará de Serra, 2020. Impresso.

Palmeiro, Cecilia. Desbunde y felicidad: de la Cartonera a Perlongher. Buenos Aires: Título, 2010. Impreso.

Pêcheux, Michel. Discurso: Estrutura ou Acontecimento. Campinas: Pontes, 1983. Impresso. 
Rodrigues, Fernanda. Língua Viva, Letra Morta: obrigatoriedade e ensino de espanhol no arquivo jurídico e legislativo brasileiro. São Paulo: Humanitas, 2012. Impresso.

Segato, Rita. «Género y colonialidad: en busca de claves de lectura y de un vocabulario estratégico descolonial.» La Cuestión Descolonial. Aníbal Quijano y Julio Mejía Navarrete (eds). Lima: Universidad Ricardo Palma - Cátedra América Latina y la Colonialidad de Poder, 2010. Impreso.

Schaeffer, Zaira. «O uso da tradução como ferramenta de ensino de Língua Estrangeira.» Portal Educação, n.d. Web. 26 abr. 2021.

Tecchio, Iliane, e Marcelina Bittencourt. «A tradução no Ensino-aprendizagem de Línguas Estrangeiras.» Revista Magistro 2.1 (2011): 152-165. Web. 26 abr. 2021.

Yerba Mala Cartonera. «El Crispín.» Yerba Mala Cartonera Blog, julio 22, 2007. Web. 24 nov. 2015. 